\title{
Behavioral Patterns of Injectable Drug Users (IDU's) In Visakhapatnam City
}

\author{
Dr. Krishnaveni Avvaru ${ }^{1}$, Dr. Krishnarao V Pasagadugula ${ }^{2}$, Dr. Rajsekhar K ${ }^{3}$, \\ Dr. S. V. Kumar ${ }^{4}$ \\ ${ }^{1}$ Professor, Department of Community Medicine, ${ }^{2}$ Asst. Professor of Dermatology, ${ }^{3}$ Internee, ${ }^{4}$ Principal, Andhra \\ Medical College, Visakhapatnam.
}

\begin{abstract}
:
Background: About 13.2 million people worldwide inject drugs, and about 10\% of all new HIV infections globally result from the use of contaminated injecting equipment by Injectable Drug Users. India is home to one of the largest HIV/AIDS epidemics in the World. In this context, there is rising concern about the large number of IDUs and the attendant risk of HIV. It was estimated that there were around 1000-1200 IDUs in Visakhapatnam. Objectives: 1)to study socio demographic profile, 2) Drug injecting behavior 3) Sexual behavior of Injectable drug users in Visakhapatnam city. Methodology: A total of 150 IDUs were contacted. A semi structured, pre tested questionnaire was administered after taking informed consent. Study variables include age, education, occupation, marital status, age at first injecting, frequency of injecting etc. Results: All 150 were males. $50 \%$ in the age group of 25-29 years, $12 \%$ were $15-19$ years of age, $63 \%$ were unemployed. $39.36 \%$ were graduates. Mean age at first injection was 18.4 years; $40 \%$ inject $4-5$ times per day and 32\% share injecting paranephrelia. Forearm was the most preferred site. Pentazocine was most commonly used drug followed by Ketasolamine. $77 \%$ had more than one sexual partner. Conclusion: The results of our study indicate that high risk behaviors are prevailing among IDUs in our area and this risk behavior is of concern and they are at risk of developing HIV and other blood borne infections.
\end{abstract}

Key words: Drug injecting behavior, Injectable drug users, Sexual behavior, Visakhapatnam.

\section{Introduction}

About 13.2 million people worldwide inject drugs, and about $10 \%$ of all new HIV infections globally result from the use of contaminated injecting equipment by Injectable Drug Users (IDUs) ${ }^{\mathbf{1}}$ Of an estimated 13.2 million people now injecting drugs, 78\% (10.1 million) are in developing countries, There are over 500000 people who inject drugs in South-East Asia, with many involved in high-risk behavior such as the sharing of non-sterile injecting equipment, and this has contributed towards the overall HIV epidemic in several countries of the Region. India is home to one of the largest HIV/AIDS epidemics in theWorld ${ }^{2}$. In this context, there is rising concern about the large number of IDUs and the attendant risk of HIV. Sentinel surveillance data from 2003 indicates a rise from $7.4 \%$ to $14.4 \%$ in HIV prevalence amongst injecting drug users in New Delhi ${ }^{3}$ Although all IDUs using potentially contaminated injecting equipment are at high risk of HIV infection, specific populations are especially susceptible to infection. These include young IDUs, because of inexperience in obtaining clean injecting equipment; female IDUs, because of sexual risk and injecting practices over which they may have less control and because of exclusion from services. Alarmed at the spurt in cases of drug abuse in Visakhapatnam, A.P State AIDS control society has started TI-IDU project on August $16^{\text {th }} 2008$ and harm reduction strategies were adopted. It was estimated that there were around 1000-1200 IDUs in Visakhapatnam ${ }^{4}$. An attempt was made to study 1) The socio demographic profile, 2) Drug injecting behavior and 3) Sexual behavior of Injectable drug users in Visakhapatnam city.

\section{Methodology}

A cross-sectional, peer led study was conducted in a de-addiction centre and some of the identified hot spots in Visakhapatnam city. A total of 150 IDUs were contacted during the period of June 2008 to November 2008. A semi structured, pre tested questionnaire was administered after taking informed consent. Study variables include age, education, occupation, marital status, age at first injecting, frequency of injecting etc. Data was analyzed using MS excel spread sheet. Approval from Institutional ethics committee was obtained to conduct the study.

\section{Results}

Total number of 150 drug injecting users were interviewed. All were males. Half of them were in the age group of 25-29 years and $12 \%$ were adolescents. Mean age of the study population was 25.2 years. Majority 
were married $(75.33 \%)$ and $16.6 \%$ were unmarried and the rest were either separated or widowed. Nearly two thirds $(63 \%)$ were unemployed by occupation.

Table No.1: Age wise distribution of study population

\begin{tabular}{|l|l|l|}
\hline Age $($ Yrs $)$ & $\mathrm{n}(\%)$ \\
\hline $15-19$ & 18 & $(12)$ \\
\hline $20-24$ & 35 & $(23.34)$ \\
\hline $25-29$ & 75 & $(50)$ \\
\hline $30-34$ & 7 & $(4.66)$ \\
\hline 35 and above & $15 \quad(10)$ \\
\hline Total & $\mathbf{1 5 0}(\mathbf{1 0 0})$ \\
\hline
\end{tabular}

Majority of the study participants were educated, almost $40 \%$ were graduates and none were illiterates. About $58 \%$ of them reside in urban slums and the rest $42 \%$ are from urban residential areas.

Table No.2: Distribution showing the educational status of the study population

\begin{tabular}{|c|c|}
\hline Education status & $\mathrm{n} \quad(\%)$ \\
\hline Primary & $(0 \%)$ \\
\hline Secondary & $8 \quad(5 \%)$ \\
\hline Higher secondary & $83 \quad(55.64 \%)$ \\
\hline Graduate and above & $\begin{array}{ll}59 & (39.36 \%) \\
\end{array}$ \\
\hline Total & $150(100 \%)$ \\
\hline
\end{tabular}

DRUG INJECTING BEHAVIOUR: Table 3 shows that majority started injecting drugs at the age of 18 and 19 years and almost $95 \%$ started injecting drugs by the age of 20 years. On further analysis it was found that mean age at first injected was 18.4 years among urban residents and 16.4 years among those residing in urban slums.

Table No.3: Distribution of the study population on the basis of the age at which first injected (drug abuse)

\begin{tabular}{|l|ll|}
\hline Age at which first injected (yrs) & $\mathrm{n}$ & $(\%)$ \\
\hline 15 & 12 & $(8 \%)$ \\
\hline 16 & 42 & $(28 \%)$ \\
\hline 17 & 8 & $(5.34 \%)$ \\
\hline 18 & 40 & $(26.66 \%)$ \\
\hline 19 & 40 & $(26.66 \%)$ \\
\hline 20 & 5 & $(3.34 \%)$ \\
\hline 21 & 3 & $(2 \%)$ \\
\hline Total & $\mathbf{1 5 0}$ & $(\mathbf{1 0 0 \%})$ \\
\hline
\end{tabular}

Regarding the frequency of drug injecting, as shown in Table 4, 40\% of IDU's stated that they inject 45 times per day and nearly one third (28\%) inject more than five times per day. When the question "did you ever shared injecting equipment" was asked, 32\% stated that they share injecting paranephrelia. Majority (68\%) preferred forearm as the site for injecting drugs.

Table No.4: Distribution of the study population on the basis of the frequency of drug injecting per day

\begin{tabular}{|l|ll|}
\hline Frequency (Times per day) & $\mathrm{n}$ & $(\%)$ \\
\hline $1-2$ & 0 & $(0 \%)$ \\
\hline $2-3$ & 25 & $(16.6 \%)$ \\
\hline $3-4$ & 23 & $(15.34 \%)$ \\
\hline $4-5$ & 60 & $(40 \%)$ \\
\hline $5-6$ & 25 & $(16.6 \%)$ \\
\hline $6-8$ & 17 & $(11.34 \%)$ \\
\hline Total & $\mathbf{1 5 0}(\mathbf{1 0 0 \%})$ \\
\hline
\end{tabular}

Pentazocine was the universal drug that is used by IDUs. $64 \%$ reported that they use penicillin also as the injecting drug. Mirazolamine was used by $46 \%$.

Table No.5: Distribution of study population according to the type of injecting drug used

\begin{tabular}{|l|ll|}
\hline Type of injecting drug used & $\mathrm{n}$ & $\%$ \\
\hline Pentazocine & 150 & 100 \\
\hline Ketasolamine & 95 & 63.3 \\
\hline Mirazolamine & 69 & 46 \\
\hline Penicillin & 96 & 64 \\
\hline
\end{tabular}

In addition to injecting drugs, IDUs were also taking oral drugs like cough syrup, nitrazepam tablets and opium inhalation. 
Table No.6: Distribution of study population according to other drugs used

\begin{tabular}{|l|ll|}
\hline Type of other drugs used & $\mathrm{n}$ & $\%$ \\
\hline Opium & 142 & 94.6 \\
\hline Nitrazepam tablets & 90 & 60 \\
\hline Corex syrup & 147 & 98 \\
\hline
\end{tabular}

Sexual behavior: when the question "did you ever had sex" was asked, $143(95.34 \%)$ stated that they had sex. Nearly $77 \%$ (110/143) admitted that they had more than one sexual partner, among whom 34 IDUs had more than 5 partners during the past 6 months. Nearly $60 \%(87 / 143)$ always use condom while having sex and the rest were occasional users. Nearly $42 \%$ (60/143) admitted that they injected drug before having sex.

Table No.7: Distribution of the study population on the basis of having sex while intoxicated (other than spouse)

\begin{tabular}{|l|l|}
\hline Ever injected drug before having sex? & $\mathrm{n}(\%)$ \\
\hline Yes & $60(41.95 \%)$ \\
\hline No & $83(58.05 \%)$ \\
\hline Total & $\mathbf{1 4 3 ( 1 0 0 \% )}$ \\
\hline
\end{tabular}

\section{Discussion}

The findings of the study provide some insight about the profiles of IDUs in relation to drug injecting behavior and sexual behavior. Most IDUs in our study were in the age group of 20-29 years indicating that it is problem of young age. Majority were literates and two-thirds were unemployed. These findings were in consistent with previous studies ${ }^{5,6,7}$. Our data also suggest that these IDUs were initiating drug injection at young age and this is in consistent with previous data ${ }^{5}$.

Many factors influence or cause needle sharing. Sterile syringes not readily available or level of awareness about safe injecting can lead to needle sharing. Sharing of injecting paranephrelia is of concern as it was $32 \%$ in our study which is consistent with Ojha SP et al. (31\%).

Effects related to drug use could influence unsafe sexual behavior and in our study, majority were sexually active with multiple sexual partners. Regular usage of condoms was also less reported indicating that there is potential risk of transmission of HIV and other STIs. Similar results were also reported in a study done in Chennai.

\section{Conclusion}

The results of our study indicate that high risk behaviors are prevailing among IDUs in our area and this risk behavior is of concern and they are at risk of developing HIV and other blood borne infections. There is need for Behavior Change Communication targeting the families of IDUs and the quality of harm reduction strategies directed to IDUs need to be monitored.

\section{Bibliography}

[1]. World Health Organization. Advocacy guide: HIV/AIDS prevention among injecting users: workshop manual / World Health Organization, UNAIDS

[2]. Avina sauna,Waimar Tun,Aruna bhattacharya,Vaishali Mahendra et.al. Injecting drug users in India:understanding sexual behaviours and sexual networks to design effective behavior change strategies. Population council dt. April 2007. (www.popcouncil.org)

[3]. WHO, UNODC, UNAIDS technical guide for countries to set targets for universal access to HIV prevention, treatment and care for injecting drug users - 2012 revision.

[4]. Injecting Drug Users - ARDAR(www.ardar.org.in/prog-injecting drug users)

[5]. Solomon SS,Desai M, Srikrishnan AK , Thamburaj E, Vasudevan CK ,Kumar MS et al "The profile of injection drug users in Chennai,India : identification of risk behaviours and implications for intervention”. Subst Use Misuse.2010 Feb;45(3):354-67

[6]. Ojha S.P, Pokharel.A, Aacharya R P, Pandey KR, Bhusal C L, Marhatta MN. Sociopsychological study among injectable drug users in Kathmandu valley. Journal of Nepal Medical Association

[7]. Elizabeth, Pisani, Purwa K. Sucahya, Octavery Kamil Saiful Jazan. Sexual behavior among injection drug users in 3 Indonesian cities carries a high potential for HIV spread to non injectors. J. Acquir. Immune Defic syndr 2003; 34:403-406 